\title{
Avaliação do potencial madeireiro na Floresta Nacional do Tapajós, após 28 anos da exploração florestal
}

\author{
Leonardo Pequeno Reis ${ }^{1}$, Ademir Roberto Ruschel ${ }^{2}$, Amanda Alves Coelho ${ }^{1}$, Adriana Santos da Luz ${ }^{1}$, Regina \\ Célia Viana Martins-Da-Silva²
}

\begin{abstract}
1Universidade Federal Rural da Amazônia, Avenida Presidente Tancredo Neves, 2501, Montese, CEP 66077-530, Belém, PA, Brasil, leopequenoreis@terra.com.br; amandaalves@yahoo.com.br; adriana.s.luz@hotmail.com; ²Embrapa Amazônia Oriental, Trav. Dr. Enéas Pinheiro s/nº, CP 48, CEP 66095-100, Belém, PA, Brasil, ruschel@cpatu.embrapa.br; regina@cpatu.embrapa.br
\end{abstract}

Resumo - A pesquisa foi conduzida em uma área experimental de 64 ha, localizada na Floresta Nacional do Tapajós, PA, Brasil. A área foi explorada em 1979 e monitorada por meio de 36 parcelas permanentes (9 ha). Com base nos dados da última medição, em 2007, as espécies foram classificadas em três categorias: arbóreas com valor comercial madeireiro (MC); com potencial comercial, sem reconhecido/consolidado valor de mercado madeireiro (MP); e espécies arbóreas sem valor comercial/industrial madeireiro (MS). Após 28 anos da exploração, foram registrados 9.859 indivíduos, com DAP $\geq 5 \mathrm{~cm}$, distribuídos em 239 espécies. Nas três categorias representadas, $35,5 \%$ foram MC. Desse total, somente 53\% apresentaram-se aptas para exploração, somando um volume de $75,5 \mathrm{~m}^{3} \mathrm{ha}^{-1}$. Observou-se que algumas espécies madeireiras foram favorecidas pela exploração em densidade e volume, como Carapa guianensis e Virola michelii, mas outras obtiveram o balanço negativo na maioria das espécies exploradas, destacando-se as espécies Astronium lecointei e Manilkara huberi. Por final, observou-se que a biomassa florestal foi recuperada, porém as espécies exploradas continuam com balanço negativo. Conclui-se que o primeiro ciclo de corte é possível, principalmente devido ao estoque dominante de espécies não exploradas na primeira colheita.

Termos para indexação: Incremento anual, primeiro ciclo de corte, recuperação do estoque de madeira.

\section{Evaluating potential timber species at the Tapajos National Forest in Para State, Brazil, 28 years after logging}

\begin{abstract}
The stock of timber species was evaluated in a 64 ha experimental area 28 years after logging. The study was carried out in the Tapajos National Forest, state of Para, Brazilian Amazon. The study area was logged in 1979 and tree species were measured from 1981 to 2007 in 36 permanent sample plots. In 2007 tree species were classified in three groups: commercial timber (MC); potentially commercial timber (MP); non-commercial timber (MS). During that period all trees with DBH $>5 \mathrm{~cm}$ were measured. In 2007, 28 years after logging 9,859 trees from 239 species were recorded. Considering the species groups $35.5 \%$ belong to $\mathrm{MC}$, and from these only $53 \%$ are available for harvesting, representing a timber volume of $75.5 \mathrm{~m}^{3} \mathrm{ha}^{-1}$. In 2007 some species as Carapa guianensis and Virola michelii had higher timber volume than before logging but other species as Astronium lecointei and Manilkara huberi had timber volume lower in 2007. In the end of the studing period, 28 years after logging, the timber volume was recovered but the harvested species did not recuperated their original basal area. Even with the high intensity of harvest occurred in the area but considering the timber volume in 2007 of those species that were not harvested in 1979, a second cutting mainly for those species could be admissible now.
\end{abstract}

Index terms: Annual increment, first cutting cycle, forest recovering after logging.

\section{Introdução}

A Amazônia brasileira representa cerca de um terço das florestas tropicais do mundo, abrigando algumas centenas de espécies de árvores, das quais, cerca de 350 já estão sendo extraídas para fins madeireiros. A região detém um volume estimado em 60 bilhões de metros cúbicos de madeira em tora, cujo valor econômico potencial pode alcançar R \$ 4 trilhões em madeira serrada (Barros \& Veríssimo, 2002).

O Estado do Pará, no ano de 2008, obteve, não apenas da Amazônia, mas do Brasil, o título de maior produtor 
de madeira nativa (Ideflor, 2008). Ao se analisar as florestas do oeste paraense e da Calha Norte, constata-se que a região comporta, com facilidade, $\mathrm{o}$ atendimento à demanda local por produtos florestais. Anualmente, os estados do Amapá, Roraima e norte do Pará produzem 450 mil metros cúbicos de madeira em tora, só a região de Santarém, PA, é responsável por $37 \%$ desse total (SFB, 2009).

De acordo com Sabogal (2006), o setor madeireiro contribui expressivamente para a economia regional e nacional e para a geração de empregos e bem-estar social. Entretanto, a baixa qualidade das operações florestais ocasiona a degradação e destruição, principalmente, das florestas amazônicas.

$\mathrm{O}$ fato de não se saber ao certo o tempo que as florestas levam para recompor o nível de estoque de colheita (ciclo de corte) e considerando as circunstâncias atuais de não estruturação das mesmas para a produção sustentável, é necessária a fixação do intervalo ótimo de ciclos de corte para atingir uma distribuição diamétrica e uma composição de espécies adequadas aos propósitos do manejo, de modo a permitir a regeneração, o crescimento e o desenvolvimento prioritariamente de árvores de valor comercial (Souza et al., 2004).

A forma de garantir o segundo corte em um espaço de tempo menor é utilizar o manejo florestal que promova a exploração dos recursos racionalmente, garantindo a manutenção da biodiversidade e sustentando a indústria madeireira que, ainda, é um dos maiores geradores de renda da região Norte. De acordo com Silva et al. (1985), o manejo da floresta tropical amazônica sob regime de rendimento sustentado constitui uma alternativa racional para produção econômica de madeira, sem o risco de produzir alterações ecológicas significativas.

Silva (1989) propôs, com aplicação do manejo florestal, para as florestas de terra firme na Amazônia brasileira, um ciclo de corte de 30 anos. Atualmente, para os planos de manejo, no Estado do Pará, de acordo com a Instrução Normativa SEMA n ${ }^{\circ} 7 / 2006$, é considerado um ciclo de corte de 35 anos para exploração até $30 \mathrm{~m}^{3}$ ha $^{-1}$. Ruschel (2008) enfatizou que os ciclos de corte preestabelecidos de 25 a 35 anos são baseados em conhecimentos teóricos que, na prática, ainda precisam ser comprovados.

O trabalho objetiva avaliar o potencial madeireiro baseado em informações de monitoramento do crescimento de uma área florestal explorada há 28 anos, para contribuir nas tomadas de decisão públicas sobre os planos de manejo florestal na Amazônia, principalmente no que se refere ao intervalo do ciclo de corte.

\section{Material e métodos}

A área de estudo está localizada na Floresta Nacional do Tapajós, à altura do $\mathrm{Km} 67\left(55^{\circ} 00^{\prime} \mathrm{W}, 2^{\circ} 45^{\prime} \mathrm{S}\right)$ da Rodovia BR-163, Cuiabá-Santarém. Abrange o bioma Amazônia e a tipologia é floresta ombrófila densa de terra firme e, segundo Dubois (1976), é classificada como floresta alta sem babaçu (Orbignya barbosiana Burret).

$\mathrm{O}$ clima da região é tropical úmido com temperatura média anual de $25^{\circ} \mathrm{C}$, é classificado como Ami pelo sistema de Köppen (Carvalho, 1980). A umidade relativa média é de $86 \%$ e a precipitação média anual é de $2.100 \mathrm{~mm}$. Apresenta topografia plana a ondulada, com ocorrência de solo tipo Latossolo Amarelo Distrófico (Costa Filho et al., 1980).

Segundo Costa Filho et al. (1980), em meados de 1945 na Floresta Nacional do Tapajós, foram exploradas seletivamente quatro espécies de alto valor comercial: pau-rosa (Aniba roseodora Ducke), maçaranduba (Manilkara huberi (Ducke) A. Chev.), freijó (Cordia goeldiana Huber) e cedro (Cedrela odorata L.). Em 64 ha da área de estudo, em 1975, foi realizado um inventário a 100\% de intensidade (Censo florestal) das espécies madeireiras com DAP $\geq 15 \mathrm{~cm}$ e, posteriormente, em 1979, realizada uma exploração intensiva de 64 espécies madeireiras, as quais acumularam em média um volume explorado de $72,5 \mathrm{~m}^{3} \mathrm{ha}^{-1}$.

As espécies que se destacaram em volume explorado foram: Hymenaea courbaril L., Carapa guianensis Aubl., Manilkara huberi, Lecythis lurida (Miers) S. A. Mori., Bertholletia excelsa Humb. \& Bonpl., Astronium lecointei Ducke, Goupia glabra Aubl., Virola michelii Heckel, Erisma uncinatum Warm. e Terminalia amazonia (J. F. Gmel) Exell, que juntas representaram $47,4 \%$ do volume total extraído. A colheita foi executada sob dois tratamentos, corte de todas as árvores com $\mathrm{DAP} \geq 45 \mathrm{~cm}$ em 39 ha e corte das árvores com DAP $\geq$ $55 \mathrm{~cm}$, em 25 ha (Costa Filho et al., 1980). Entretanto, no presente estudo, os tratamentos foram considerados conjuntamente, formando apenas uma comunidade, visto a alta similaridade constatada nas comparações realizadas (Ruschel, 2008). Em 1981 foram instaladas, aleatoriamente, 36 parcelas permanentes $(50 \mathrm{~m}$ x $50 \mathrm{~m})$ na área de estudo. Nessas parcelas, todas as plantas com $\mathrm{DAP} \geq 5 \mathrm{~cm}$ foram identificadas botanicamente in loco 
ou, em caso de dúvida, foram coletadas amostras para posterior identificação no Herbário IAN da Embrapa Amazônia Oriental. As remedições nas parcelas foram efetuadas nos anos de 1982, 1983, 1985, 1987, 1992, 1997 e 2007.

Neste estudo, usou-se a medição de 2007 para caracterizar o potencial madeireiro atual e foram feitas análises do incremento periódico anual (IPA) entre 1981 e 2007, com base de dados obtidos no monitoramento em parcelas permanentes. Também foram feitas comparações de densidade (árvores ha $\left.{ }^{-1}\right)$ e volume $\left(\mathrm{m}^{3}\right.$ $\mathrm{ha}^{-1}$ ) entre as dez espécies com maior intensidade de extração volumétrica, relacionando o censo florestal (1975) com o inventário amostral (2007) e o IPA dessas espécies entre 1981 e 2007.

Os dados foram processados e analisados com o auxílio do Monitoramento de Florestas Tropicais (MFT) (Software Embrapa Amazônia Oriental). Os parâmetros observados foram densidade absoluta (árvores ha $\left.{ }^{-1}\right)$, volume $\left(\mathrm{m}^{3} \mathrm{ha}^{-1}\right)$, distribuição diamétrica $(\mathrm{cm})$ e incremento periódico anual (IPA).

Para se conhecer o valor madeireiro atual da floresta, as espécies foram classificadas em três categorias, conforme uso da madeira: espécies arbóreas com valor comercial madeireiro (MC); espécies arbóreas com potencial para serem comercializadas, porém sem valor comercial madeireiro reconhecido/consolidado (MP); e espécies arbóreas sem valor comercial/industrial madeireiro (MS). Na classificação, foi utilizada lista de espécies atualmente comercializadas (madeira serrada) na região de Santarém, PA.

Os volumes de madeira foram calculados pelas equações propostas por Silva \& Araújo (1984) e Silva et al. (1984) para árvores com diâmetros de $20 \mathrm{~cm}$ a 45 $\mathrm{cm}\left(\mathrm{V}=-0,0994+(9,1941) 10^{-4} \mathrm{~d}^{2}, \mathrm{com} \mathrm{R}^{2}=0,96\right)$ e para diâmetros acima de $45 \mathrm{~cm}(\ln \mathrm{V}=-7,62812+2,1809 \ln$ $\mathrm{d}$, com $\left.\mathrm{R}^{2}=0,84\right)$.

Onde: $\mathrm{V}=$ volume comercial com casca; $\mathrm{d}=\mathrm{DAP}$ de cada árvore (medição tomada a 1,30 $\mathrm{m}$ do solo) e; $\ln =$ logaritmo natural.

\section{Resultados e discussão}

\section{Composição florística}

Após 28 anos da exploração, foram encontradas 1.095 árvores ha ${ }^{-1}$ com o DAP $\geq 5 \mathrm{~cm}$ na amostra analisada (9 ha $=9.859$ árvores), distribuídas em 54 famílias botânicas, 160 gêneros e 239 espécies (Tabela 1), incluindo 26 espécimes que foram identificadas somente em nível de gênero e cinco não identificadas, devido à impossibilidade de coleta de material botânico fértil.

Tabela 1. Abundância das espécies Madeireiras (MC), Potenciais (MP) e Sem valor madeireiro (MS), registradas em 2007, na Floresta Nacional do Tapajós, Km 67.

\begin{tabular}{|c|c|c|c|c|c|}
\hline \multirow{2}{*}{ Família } & \multirow{2}{*}{ Nome vernacular } & \multirow{2}{*}{ Espécies } & \multicolumn{3}{|c|}{ Abundância } \\
\hline & & & MC & MP & MS \\
\hline Achariaceae & Farinha-seca & Lindackeria paraensis Kuhlm & - & - & 2,7 \\
\hline \multirow[t]{4}{*}{ Anacardiaceae } & Aroeira & Astronium gracile Engl. & 3,7 & - & - \\
\hline & Muiracatiara & Astronium lecointei Ducke & 0,1 & - & - \\
\hline & Tatapiririca & Tapirira guianensis Aubl. & - & 12,1 & - \\
\hline & Breu-de-leite & Thyrsodium spruceanum Benth. & - & 1,9 & - \\
\hline \multirow[t]{7}{*}{ Annonaceae } & Embirataia & Annona ambotay Aubl. & - & - & 0,4 \\
\hline & Araticum & Annona montana Macfad. & - & - & 0,2 \\
\hline & Envira-amarela & Bocageopsis multiflora (Mart.) R.E.Fr. & - & - & 2 \\
\hline & Envira-surucucu & Duguetia surinamensis R.E. Fr. & - & - & 3 \\
\hline & Envira-preta & Guatteria poeppigiana Mart. & - & - & 15,7 \\
\hline & Embireira & Xylopia benthamii R.E.Fr. & - & 0,2 & - \\
\hline & Envira & Indeterminadas & - & - & 0,2 \\
\hline
\end{tabular}


Tabela 1. Continuação.

\begin{tabular}{|c|c|c|c|c|c|}
\hline \multirow{2}{*}{ Família } & \multirow{2}{*}{ Nome vernacular } & \multirow{2}{*}{ Espécies } & \multicolumn{3}{|c|}{ Abundância } \\
\hline & & & MC & MP & MS \\
\hline \multirow[t]{8}{*}{ Apocynaceae } & Pepino-do-mato & Ambelania acida Aubl. & - & - & 1,7 \\
\hline & Araracanga & Aspidosperma spp. & 1,7 & - & - \\
\hline & Carapanaúba & Aspidosperma auriculatum Markgr. & - & 0,7 & - \\
\hline & Quinarana & Geissospermum sericeum Miers & - & - & 0,9 \\
\hline & Pau-de-colher & Lacmellea aculeata (Ducke) Monach. & - & - & 3,9 \\
\hline & Grão-de-galo & Rauvolfia sp. & - & - & 0,1 \\
\hline & Culhão-de-bode & Spongiosperma grandiflorum (Huber) Zarucchi & - & - & 0,4 \\
\hline & Pocoró & Tabernaemontana laeta Mart. & - & - & 0,1 \\
\hline Araliaceae & Morototó & Schefflera morototoni (Aubl.) Maguire, Steyerm \& Frodin & 4,3 & - & - \\
\hline \multirow[t]{2}{*}{ Bignoniaceae } & Parapará & Jacaranda copaia (Aubl.) D. Don & 10,3 & - & - \\
\hline & Ipê-amarelo & Tabebuia serratifolia (Vahl) Nichols. & 0,3 & - & - \\
\hline Bixaceae & Urucu-da-mata & Bixa arborea Huber & - & - & 61,3 \\
\hline \multirow[t]{2}{*}{ Boraginaceae } & Freijó-branco & Cordia bicolor A. DC. & - & 18,4 & - \\
\hline & Uruá & Cordia ulei I. M. Johnst. & - & 10,7 & - \\
\hline \multirow[t]{5}{*}{ Burseraceae } & Breu & Protium sp. & & & \\
\hline & Breu-fl-gr. & Protium robustum (Swart) D. M. Porter & - & 22,3 & - \\
\hline & Breu-peludo & Protium pilosissimum Engl. & & & \\
\hline & Breu-vermelho & Protium altsonii Sandwith & - & 53,4 & - \\
\hline & Breu-sucuruba & $\begin{array}{l}\text { Trattinnickia burserifolia Mart. } \\
\text { Trattinnickia rhoifolia Willd }\end{array}$ & 1,8 & - & - \\
\hline Caricaceae & Mamuí & Jacaratia spinosa (Aubl.) ADC. & - & - & 1 \\
\hline \multirow[t]{2}{*}{ Caryocaraceae } & Piquiarana & Caryocar glabrum (Aubl.) Pers. & 1 & - & - \\
\hline & Pequiá & Caryocar villosum (Aubl.) Pers. & 0,7 & - & - \\
\hline \multirow[t]{3}{*}{ Celastraceae } & Chichuarana & Cheiloclinium cognatum (Miers.) A. C. Smith. & - & - & 0,2 \\
\hline & Chichuá & Maytenus floribunda Reiss. & & & - \\
\hline & Barbatimão & Maytenus pruinosa Reiss. & - & 1,9 & - \\
\hline \multirow[t]{2}{*}{ Chrysobalanaceae } & Macucú & Licania heteromorpha Benth. & - & 2,4 & - \\
\hline & Caripé-da-folha-redonda & Licania sp. & - & 0,8 & - \\
\hline \multirow[t]{5}{*}{ Clusiaceae } & Bacuri-da-mata & Garcinia macrophylla Mart. & - & 1,6 & - \\
\hline & Anani & Symphonia globulifera L.f. & 3,4 & - & - \\
\hline & Lacre-branco & Vismia cayennensis (Jacq.) Pers. & - & - & 0,7 \\
\hline & Lacre-vermelho & Vismia guianensis (Aubl.) Choisy & - & - & 0,6 \\
\hline & Lacre & Vismia japurensis Reich. & - & - & 0,3 \\
\hline Combretaceae & $\begin{array}{l}\text { Cuiarana-do-caroço } \\
\text { Cuiarana do fruto alado }\end{array}$ & $\begin{array}{l}\text { Buchenavia sp. } \\
\text { Terminalia amazonia (J. F. Gmel.) Exell }\end{array}$ & 1,3 & - & - \\
\hline Connaraceae & Cunário & Connarus erianthus Benth. ex. Baker. & - & - & 1,4 \\
\hline Ebenaceae & Caqui & $\begin{array}{l}\text { Diospyros santaremnensis Sandw. } \\
\text { Diospyros cavalcantei Sothers. }\end{array}$ & - & 1,4 & - \\
\hline Elaeocarpaceae & $\begin{array}{l}\text { Urucurana fl. pq. } \\
\text { Urucurana fl. gr. }\end{array}$ & $\begin{array}{l}\text { Sloanea guianensis (Aubl.) Benth. } \\
\text { Sloanea. grandis Ducke }\end{array}$ & - & - & 3,8 \\
\hline
\end{tabular}


Tabela 1. Continuação.

\begin{tabular}{|c|c|c|c|c|c|}
\hline \multirow{2}{*}{ Família } & \multirow{2}{*}{ Nome vernacular } & \multirow{2}{*}{ Espécies } & \multicolumn{3}{|c|}{ Abundância } \\
\hline & & & MC & MP & MS \\
\hline \multirow[t]{8}{*}{ Euphorbiaceae } & Urucucana & Aparisthmium cordatum (A.Juss.) Baill. & - & - & 31,6 \\
\hline & Café-bravo & Dodecastigma integrifolium (Lanj.) Lanj. \& Sandw. & - & - & 0,4 \\
\hline & Mirindiba-doce & Glycydendron amazonicum Ducke & 1,6 & - & - \\
\hline & Seringueira & Hevea brasiliensis (Willd. ex A. Juss.) Müll. Arg. & 7,7 & - & - \\
\hline & Taquari & Mabea caudata Pax \& K. Hoffm. & - & - & 9,9 \\
\hline & Arataciurana & Pausandra trianae (Müll.Arg.) Baill. & - & - & 14,7 \\
\hline & Arataciú & Sagotia racemosa Baill. & - & 2,1 & - \\
\hline & Burra-leiteira & Sapium marmieri Huber & - & - & 0,2 \\
\hline \multirow[t]{13}{*}{ Lecythidaceae } & Castanha-do-pará & Bertholletia excelsa Humb. \& Bonpl. & 3,4 & - & - \\
\hline & Tauari peludo & Couratari guianensis Aubl. & 0,2 & - & - \\
\hline & Tauari-oblongifolia & Couratari oblongifolia Ducke \& R. Knuth & 0,3 & - & - \\
\hline & Tauari-stelata & Couratari stellata A.C. Sm. & 18 & - & - \\
\hline & Tauari-vermelho & Couratari tauari Berg. & 0,1 & - & - \\
\hline & Matamatá-ci & Eschweilera amazonica R. Knuth & - & 0,2 & - \\
\hline & Matamatá-branco & Eschweilera coriacea (A. DC) S.A.Mori & - & 17,9 & - \\
\hline & Matamatá-jibóia & Eschweilera ovata (Cambess.) Miers & - & 0,2 & - \\
\hline & Matamatá & Eschweilera spp. & - & 11 & - \\
\hline & Jeniparana & Gustavia augusta L. & - & - & 3,4 \\
\hline & Matamatá vermelho & Lecythis idatimon Aubl. & - & 12 & - \\
\hline & Jarana & Lecythis lurida (Miers) S. A. Mori & 6,3 & - & - \\
\hline & Castanha-sapucaia & Lecythis pisonis Camb. & 0,4 & - & - \\
\hline \multirow[t]{15}{*}{$\begin{array}{l}\text { Leguminosae } \\
\text { Caesalpinioideae }\end{array}$} & Amarelão & Apuleia leiocarpa (Vog.) J.F. Macbr. & 0,3 & - & - \\
\hline & Pata-de-vaca & Bauhinia macrophylla Poir & - & - & 0,2 \\
\hline & Fava-mari-mari & Cassia leiandra Benth. & - & - & 0,1 \\
\hline & Muirapixuna & Chamaecrista sp. & 0,1 & - & - \\
\hline & Copaíba & Copaifera reticulata Ducke & 0,7 & - & - \\
\hline & Jutairana & Swartzia arborensis (Aubl.) Pittier & - & 0,1 & - \\
\hline & Jutaí-pororoca & Dialium guianense (Aubl.) Sandw. & - & 1,4 & - \\
\hline & Cocão & Eperua bijuga Mart. ex Benth. & 11,3 & - & - \\
\hline & Apazeiro & Eperua schomburgkiana Benth. & 0,3 & - & - \\
\hline & Coataquiçaua & Peltogyne paradoxa Ducke & 0,6 & - & - \\
\hline & Taxi-vermelho & Tachigali chrysophylla (Poepp.) Zarucchi \& Herend. & 13,7 & - & - \\
\hline & Taxi-branco & Tachigali guianensis (Benth.) Zarucchi \& Herend. & - & 0,9 & - \\
\hline & Taxi-preto & Tachigali spp. & - & 0,3 & - \\
\hline & Taxi-preto-folha-grauda & Tachigali myrmecophyla (Ducke) Ducke & - & 6,3 & - \\
\hline & Pau-ponga & Tachigali sp. & 8,4 & - & - \\
\hline
\end{tabular}


Tabela 1. Continuação.

\begin{tabular}{|c|c|c|c|c|c|}
\hline \multirow{2}{*}{ Família } & \multirow{2}{*}{ Nome vernacular } & \multirow{2}{*}{ Espécies } & \multicolumn{3}{|c|}{ Abundância } \\
\hline & & & MC & MP & MS \\
\hline \multirow[t]{15}{*}{$\begin{array}{l}\text { Leguminosae } \\
\text { Mimosoideae }\end{array}$} & Ingá-chumbinho & Abarema cochleata (Willd.) Barneby \& JW Grimes & - & 7,4 & - \\
\hline & Fava-mapuxiqui & $\begin{array}{l}\text { Balizia elegans (Ducke) Barneby \& J. W. Grimes } \\
\text { Balizia pedicellaris (DC.) Barneby \& J. W. Grimes }\end{array}$ & 1,6 & - & - \\
\hline & Faveira & Dimorphandra polyandra Benoist. & - & 0,1 & - \\
\hline & Fava-timbaúba & Enterolobium maximum Ducke & 0,2 & - & - \\
\hline & Fava-de-rosca & Enterolobium schomburgkii (Benth.) Benth. & 1 & - & - \\
\hline & Ingá & Inga spp. & & & \\
\hline & Ingá-vermelho & Inga alba (Sw.) Willd. & - & 64 & - \\
\hline & Ingá-xixica & Inga heterophylla Willd. & 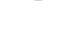 & T & 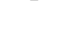 \\
\hline & Ingá & Inga stipularis $\mathrm{DC}$. & & & \\
\hline & Fava-arara-tucupi & Parkia multijuga Benth. & 2,1 & - & - \\
\hline & Fava-bolota & Parkia pendula (Willd.) Benth. ex Walp. & 0,9 & - & - \\
\hline & Fava-timborana & Pseudopiptadenia suaveolens (Miq.) J. W. Grimes & 5 & - & - \\
\hline & Fava-barbatimão & Stryphnodendron pulcherrimum (Willd.) Hochr. & - & 2,4 & - \\
\hline & Ingarana & Zygia sp. & - & 0,1 & - \\
\hline & Angelim-rajado & Zygia racemosa (Ducke) Barneby \& J. W. Grimes & 1 & - & - \\
\hline \multirow{16}{*}{$\begin{array}{l}\text { Leguminosae } \\
\text { Papilionoideae }\end{array}$} & Melancieira & Alexa grandiflora Ducke & 8,2 & - & - \\
\hline & Sucupira-preta & Bowdichia virgilioides Kunth & 0,3 & - & - \\
\hline & Cumaru & Dipteryx odorata (Aubl.) Willd. & 0,7 & - & - \\
\hline & Cumarurana & Dipteryx alata Vogel & 0,9 & - & - \\
\hline & Aquiqui & Derris spruceana (Benth.) Ducke & - & - & 0,2 \\
\hline & Jutaí-açu & Hymenaea courbaril L. & 1,2 & - & - \\
\hline & Jutaí-mirim & Hymenaea parvifolia Huber. & 0,3 & - & - \\
\hline & Angelim-da-mata & Hymenolobium excelsum Ducke & 0,7 & - & - \\
\hline & $\begin{array}{l}\text { Tento-mulato } \\
\text { Tento }\end{array}$ & $\begin{array}{l}\text { Ormosia nobilis Tul. var. santaremnensis (Ducke) Rudd. } \\
\text { Ormosia paraensis Ducke }\end{array}$ & 5,3 & - & - \\
\hline & Macacaúba & Platymiscium filipes Benth. & 0,7 & - & - \\
\hline & Cocão/gema-de-ovo & Amphiodon effusa Huber & - & 0,6 & - \\
\hline & Mututi & Pterocarpus santalinoides L'Hér. ex DC. & - & 0,9 & - \\
\hline & Gombeira-falsa & Swartzia polyphylla DC. & & & \\
\hline & Gombeira-vermelha & Swartzia grandifolia Bong. ex Benth & 11,8 & - & - \\
\hline & Gombeira & Swartzia spp. & & & \\
\hline & Fava-amargosa & Vatairea paraensis Ducke & 1,7 & - & - \\
\hline Goupiaceae & Cupiúba & Goupia glabra Aubl. & 2,3 & - & - \\
\hline \multirow[t]{2}{*}{ Humiriaceae } & Uchi & Endopleura uchi (Huber) Cuatrec. & 2,6 & - & - \\
\hline & Uchirana & Vantanea guianensis Aubl. & 0,1 & - & - \\
\hline Icacinaceae & Umarirana & Poraqueiba guianensis Aubl. & - & - & 0,1 \\
\hline Lacistemaceae & Mata-calado-falso & Lacistema aggregatum (P. J. Bergius) Rusby & - & - & 0,9 \\
\hline Lamiaceae & Tarumã & Vitex triflora Vahl. & - & 0,3 & - \\
\hline
\end{tabular}


Tabela 1. Continuação.

\begin{tabular}{|c|c|c|c|c|c|}
\hline \multirow{2}{*}{ Família } & \multirow{2}{*}{ Nome vernacular } & \multirow{2}{*}{ Espécies } & \multicolumn{3}{|c|}{ Abundância } \\
\hline & & & MC & MP & MS \\
\hline \multirow[t]{13}{*}{ Lauraceae } & Pau-rosa & Aniba roseodora Ducke & 1,6 & - & - \\
\hline & Canela-caxeta & Licaria cannella (Meissn.) Kostermans & 7 & - & - \\
\hline & Itaúba & Mezilaurus itauba (Meissn.) Taub. ex Mez & 0,1 & - & - \\
\hline & Itaúba-amarela & Mezilaurus lindaviana Schwacke \& Mez & 1,6 & - & - \\
\hline & Preciosa & Aniba canelilla (Kunth) Mez & & & \\
\hline & Louro-preto & Endlicheria bracteata $\mathrm{Mez}$ & & & \\
\hline & Louro-preto & Nectandra cuspidata Nees & & & \\
\hline & Louro-prata & Ocotea guianensis Aubl. & & & \\
\hline & Louro-preto & Ocotea opifera Mart. & 24 & - & - \\
\hline & & Ocotea costulata (Nees) Mez & & & \\
\hline & & Ocotea caudata (Nees) Mez & & & \\
\hline & Louro & Ocotea baturitensis Vattimo & & & \\
\hline & & Indeterminadas & & & \\
\hline Malpighiaceae & Murici-da-mata & Byrsonima crispa A. Juss & - & 0,7 & - \\
\hline \multirow[t]{7}{*}{ Malvaceae } & Pente-de-macaco-pluma & Apeiba tibourbou Aubl. & - & 0,2 & - \\
\hline & Pente-de-macaco-disco & Apeiba echinata Gaertn. & - & 9,3 & - \\
\hline & Mamorana & Bombacopsis nervosa (Uitt.) A. Robyns & - & 4 & - \\
\hline & Açoita-cavalo & Luehea speciosa Willd. & 0,1 & - & - \\
\hline & Inajarana & Quararibea guianensis Aubl. & - & - & 8,9 \\
\hline & Axixá & Sterculia pilosa Ducke & 4 & - & - \\
\hline & Cacau-da-mata & Theobroma speciosum Willd. Ex Spreng. & - & - & 10,7 \\
\hline \multirow[t]{4}{*}{ Melastomataceae } & Muúba & Bellucia grossularioides (L.) Triana & - & - & 1,2 \\
\hline & Canela-de-veado & Miconia guianensis (Aubl.) Cogn. & - & - & 3,3 \\
\hline & Papaterra & Miconia spp. & - & - & 33,1 \\
\hline & Muiraúba & Mouriri nigra (DC.) Morley & - & 0,2 & - \\
\hline \multirow[t]{3}{*}{ Meliaceae } & Andiroba & Carapa guianensis Aubl. & 17,6 & - & - \\
\hline & Andirobarana & Guarea guidonia (L.) Sleumer & - & 0,9 & - \\
\hline & Jataúba & Trichilia spp. & - & - & 5,6 \\
\hline \multirow[t]{15}{*}{ Moraceae } & Tatajuba & Bagassa guianensis Aubl. & 0,1 & - & - \\
\hline & Mururé & Brosimum acutifolium Huber & - & 1,7 & - \\
\hline & Amapá-amargoso & Brosimum guianense (Aubl. ) Huber & 3,3 & - & - \\
\hline & Amapá-doce & Brosimum parinarioides Ducke & 2,1 & - & - \\
\hline & Amapaí & Brosimum lactescens (S. Moore) C. C. Berg & 1,4 & - & - \\
\hline & Caucho & Castilla ulei Warb. & - & 1,3 & - \\
\hline & Janitá & Clarisia ilicifolia (Spreng. ) Lanj. \& Rossberg & 10,1 & - & - \\
\hline & Guariúba & Clarisia racemosa Ruiz \& Pavon & 0,4 & - & - \\
\hline & Caxinguba & Ficus maxima Mill. & - & - & 0,2 \\
\hline & Inharé & Helicostylis pedunculata Benoist. & - & 11,6 & - \\
\hline & Muiratinga & Maquira sclerophylla (Ducke) C.C. Berg & - & 5,1 & - \\
\hline & Panã & Naucleopsis concinna (Standl.) C. C. Berg. & - & - & 0,1 \\
\hline & Muiratinga-da-folha-grande & Perebea guianensis Aubl. & - & 25,9 & - \\
\hline & Pama & Perebea mollis (Poepp. \& Endl.) Huber & - & 2,7 & - \\
\hline & Muiratinga-folha-peluda & Pseudolmedia laevis (Ruiz \& Pav.) J. F. Macbr. & - & - & 0,1 \\
\hline
\end{tabular}


Tabela 1. Continuação.

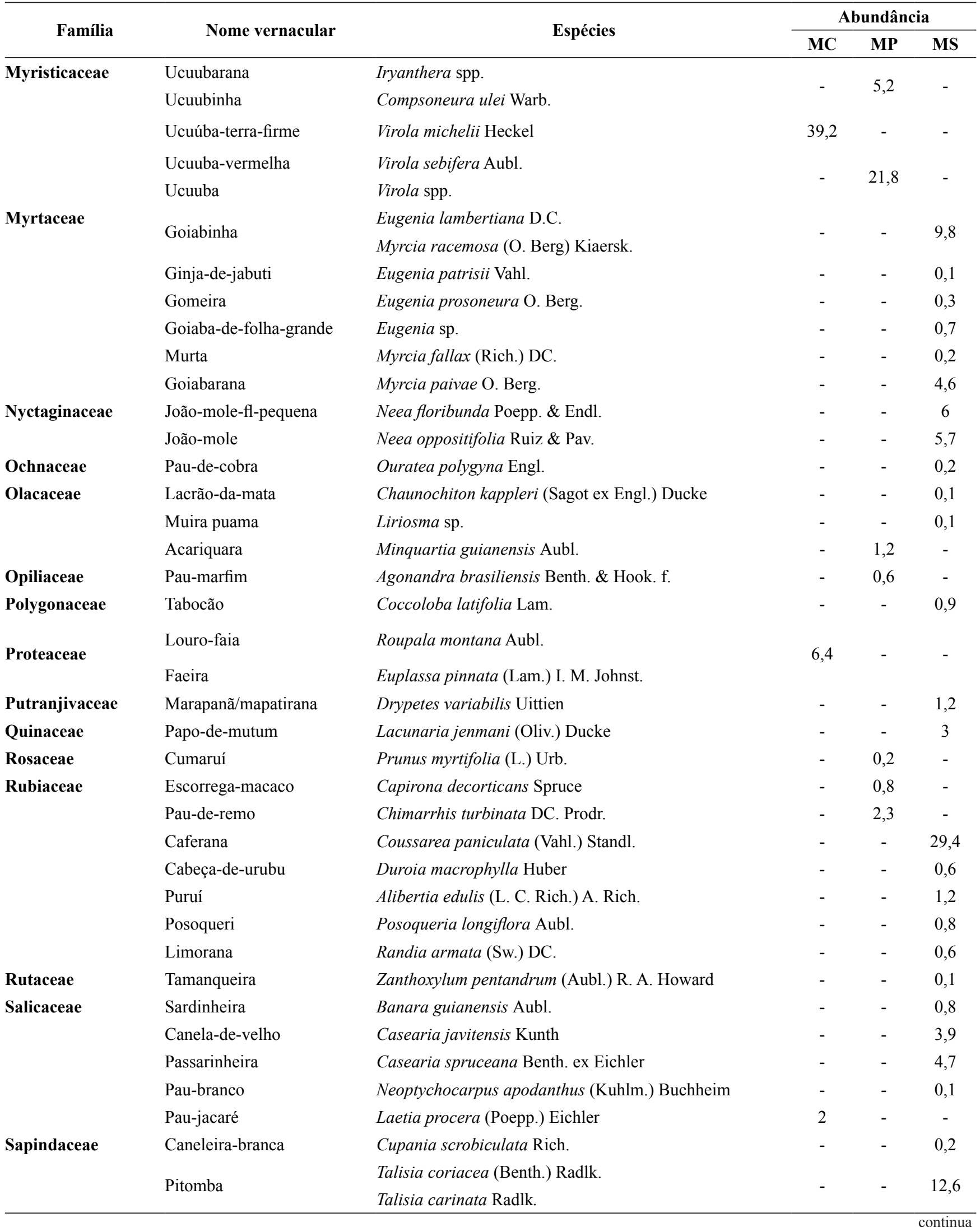


Tabela 1. Continuação.

\begin{tabular}{|c|c|c|c|c|c|}
\hline \multirow{2}{*}{ Família } & \multirow{2}{*}{ Nome vernacular } & \multirow{2}{*}{ Espécies } & \multicolumn{3}{|c|}{ Abundância } \\
\hline & & & MC & MP & MS \\
\hline \multirow[t]{13}{*}{ Sapotaceae } & Maçaranduba & Manilkara huberi (Ducke) A. Chev. & 2,8 & - & - \\
\hline & Abiu-mangabinha & Micropholis venulosa (Mart. \& Eichler) Pierre. & 1,1 & - & - \\
\hline & Goiabão & Pouteria bilocularis (H. Winkl. ) Baehni & 3,1 & - & - \\
\hline & Abiu-cutite & Pouteria macrophylla (Lam.) Eyma & - & 37,6 & - \\
\hline & Abiu-vermelho & Pouteria guianensis Aubl. & 1,3 & - & - \\
\hline & Abiu-fl.-prateada & Pouteria filipes Eyma & & & \\
\hline & Abiu-rosadinho & Pouteria anomala (Pires) T. D. Penn. & & & \\
\hline & Abiu-fl.-peluda & Ecclinusa abbreviata Ducke & & & \\
\hline & Guajará-bolacha & Pouteria oppositifolia (Ducke) Baehni & & & \\
\hline & & Pouteria laurifolia (Gomes) Radlk & - & 9,9 & - \\
\hline & & Pouteria cladantha Sandwith & & & \\
\hline & Abiu & Pouteria egensis (A. DC.) Baehni & & & \\
\hline & & Indeterminadas & & & \\
\hline \multirow[t]{2}{*}{ Simaroubaceae } & Pau-para-tudo & Simaba cedron Planch. & - & - & 2,8 \\
\hline & Marupá & Simarouba amara Aubl. & 1,9 & - & - \\
\hline Siparunaceae & Capitiú & Siparuna decipiens (Tul.) A. DC & 2,7 & - & - \\
\hline Ulmaceae & Mentira & Ampelocera sp. & - & - & 0,1 \\
\hline \multirow[t]{5}{*}{ Urticaceae } & Embaúba-branca & Cecropia obtusa Trécul & - & 4,6 & - \\
\hline & Embaúba-torém & Cecropia sciadophylla Mart. & - & 7,9 & - \\
\hline & Embaúba-vermelha & Cecropia palmata Willd. & - & 0,2 & - \\
\hline & Embaubarana & Pourouma guianensis Aubl. & - & 7,8 & - \\
\hline & Mapatirana & Pourouma minor Benoist. & - & - & 0,1 \\
\hline \multirow[t]{5}{*}{ Violaceae } & Paparola & Paypayrola grandiflora Tul. & - & - & 1,7 \\
\hline & Acariquarana & Rinorea guianensis Aubl. & - & 49,4 & - \\
\hline & & Rinorea flavescens (Aubl.) Kuntze & & & \\
\hline & Canela-de-jacamim & Rinorea neglecta Sandwith & - & - & 19,2 \\
\hline & & Rinorea falcata (Mart. ex Eichler) Kuntze & & & \\
\hline \multirow[t]{3}{*}{ Vochysiaceae } & Quarubarana & Erisma uncinatum Warm. & 1,7 & - & - \\
\hline & Mandioqueira-áspera & Qualea paraensis Ducke & 0,1 & - & - \\
\hline & Quaruba-verdadeira & Vochysia maxima Ducke & 1,4 & - & - \\
\hline Indeterminadas & A identificar & A identificar & - & - & 0,7 \\
\hline Total (árvores ha' ${ }^{-1}$ ) & & & 288 & 469,3 & 338 \\
\hline Porcentagem (\%) & & & 26,3 & 42,8 & 30,9 \\
\hline
\end{tabular}

As famílias com o maior número de espécies foram, em ordem decrescente: Leguminosae (Mimosoideae-16, Caesalpinioideae-15 e Papilionoideae-14), Moraceae (16) e Lecythidaceae (13), que juntas ocuparam quase um terço do total de espécies (31\%). Em relação à abundância absoluta (árvores $\mathrm{ha}^{-1}$ ), as famílias que se destacaram foram, em ordem decrescente: Leguminosae (Mimosoideae- 85,9, Caesalpinioideae-
44,9 e Papilionoideae- 33,2), Burseraceae $(74,2)$ e Lecythidaceae $(73,7)$, que juntas representaram $28,8 \%$ dos indivíduos amostrados. Em conformidade com outros estudos, Leguminosae, Burceraceae, Lecythidaceae e Moraceae demonstraram predominância na estrutura florística do bioma amazônico, independente de ser explorada ou não (Lopes et al., 1989; Costa et al., 1998; Sandel \& Carvalho, 2000; Francez et al., 2007; Ruschel, 
2008), diferenciando-se do Bioma Mata Atlântica, no qual há dominância característica das Leguminosae, Lauraceae e Myrtaceae (Ruschel et al., 2009).

Das 239 espécies, 35,5\% (85) foram classificadas como MC (madeira comercial), representadas por $26,3 \%$ dos indivíduos da área, $31,4 \%$ espécies (75) MP (madeira potencial), representadas por $42,7 \%$ dos indivíduos, e $33,1 \%$ (79) em MS (madeira sem valor), representados por $31 \%$ dos indivíduos. A alta diversidade de espécies arbóreas na Amazônia é destacável ao se comparar a diversidade de espécies arbóreas madeireiras em 13 remanescentes florestais da Mata Atlântica. Nessa, Ruschel et al. $(2003 ; 2005)$ registraram 63 espécies.

As famílias com maior número de indivíduos (árvores ha-1) classificados como $\mathrm{MC}$ foram, em ordem decrescente: Leguminosae (Caesalpinioideae- 35,4 distribuídos em oito espécies, Papilionoideae- 31,8, em 11 espécies e Mimosoideae- 11,8, em oito espécies), Myristicaceae- 39,2 representada por uma única espécie (Virola michelii), Lauraceae- 34,2 por 11 espécies, Lecythidaceae- 28,9 por sete espécies e Meliaceae17,6 representada por uma única espécie (Carapa guianensis). Essas famílias juntas ocuparam $69 \%$ dos indivíduos amostrados na classe MC.

As espécies que apresentaram o maior número de indivíduos (árvores $\mathrm{ha}^{-1}$ ) foram, em ordem decrescente: Bixa arborea $\left(61,3 \mathrm{ha}^{-1}\right)$, Protium altsonii $\left(53,4 \mathrm{ha}^{-1}\right)$, Rinorea guianensis $\left(49,4 \mathrm{ha}^{-1}\right)$, Virola michelii $\left(39,2 \mathrm{ha}^{-1}\right)$ e Pouteria macrophylla $\left(37,6 \mathrm{ha}^{-1}\right)$, que juntas ocuparam $30 \%$ dos indivíduos amostrados. Espécies pioneiras após a exploração florestal se beneficiaram com a abertura do dossel gerada pela exploração. Essas aumentaram, fortemente, a abundância em comparação com as florestas não exploradas. Oliveira et al. (2005) também observaram em área pós-explorada, distante, aproximadamente, 50 $\mathrm{km}$ da área do presente estudo, a forte dominância de espécies pioneiras de baixo valor comercial, como Bixa arborea e Inga spp. Alder \& Silva (2001) enfatizaram que a maior parte da regeneração após exploração de alta intensidade é constituída por espécies pioneiras com madeira sem valor comercial, como espécies do gênero Inga. De acordo com Lopes et al. (2002), a espécie Bixa arborea também apresentou alta densidade em área atingida por queimada em uma Floresta Estacional Semidecidual Submontana, Mata Atlântica. Isso demonstra que a espécie é adaptada para ocupar os ambientes com distúrbios que resultam em grandes clareiras.
Em relação à classificação, as espécies $\mathrm{MC}$ com maior número de indivíduos (árvores $\mathrm{ha}^{-1}$ ) foram, em ordem decrescente: Virola michelii $\left(39,2 \mathrm{ha}^{-1}\right)$, Couratari stellata $\left(18 \mathrm{ha}^{-1}\right)$, Carapa guianensis $\left(17,6 \mathrm{ha}^{-1}\right) \mathrm{e}$ Tachigali chrysophylla $\left(13,7 \mathrm{ha}^{-1}\right)$, que juntas ocuparam $30,7 \%$ nessa categoria e $8,1 \%$ da comunidade florestal. As espécies classificadas como MP com maior número de indivíduos foram, em ordem decrescente: Protium altsonii $\left(53,4 \mathrm{ha}^{-1}\right)$, Rinorea guianensis $\left(49,4 \mathrm{ha}^{-1}\right)$, Pouteria macrophylla $\left(37,6\right.$ ha $\left.^{-1}\right)$ e Perebea guianensis $\left(25,9 \mathrm{ha}^{-1}\right)$, que juntas ocuparam $35,5 \%$ dos indivíduos nessa categoria e $15,2 \%$ da comunidade florestal. As espécies com maior número de indivíduos (árvores ha-1) classificados como MS foram, em ordem decrescente: Bixa arborea $\left(61,3 \mathrm{ha}^{-1}\right)$, Aparisthmium cordatum $(31,6$ ha $\left.^{-1}\right)$, Coussarea paniculata $\left(29,4\right.$ ha $\left.^{-1}\right)$ e Guatteria poeppigiana $\left(15,7 \mathrm{ha}^{-1}\right)$, que juntas ocuparam $40,8 \%$ dos indivíduos nessa classe e $12,9 \%$ da comunidade florestal. Deve-se realçar que vários gêneros apresentaram alta abundância, por exemplo, Inga, Protium e Rinorea, embora tenham sido representadas por várias espécies.

\section{Distribuição diamétrica}

Após 28 anos da exploração, 96,7\% dos indivíduos possuem diâmetro inferior a $45 \mathrm{~cm}$, o que antes da exploração foi praticamente $20 \%$ inferior (Ruschel, 2008), demonstrandro que a extração foi muito pesada $\left(72 \mathrm{~m}^{3} \mathrm{ha}^{-1}\right)$.

Segundo Braz (2010), a colheita das árvores nas classes de maior diâmetro $(65 \mathrm{~cm}$ e $75 \mathrm{~cm})$ que mais contribuem no incremento florestal reduz drasticamente a capacidade de recuperação da floresta, apontando a necessidade de longos períodos para tal recuperação (Sist \& Ferreira, 2007). Porém, dos 3,3\% dos indivíduos com DAP $\geq 45 \mathrm{~cm}, 68 \%$ foram classificados como MC, demonstrando que o diâmetro é uma das características que contribuem para o uso comercial, o que em parte explica o valor comercial desconhecido das espécies que não atingem diâmetros adequados comercialmente e/ou por critérios da legislação ambiental.

A floresta, na área de estudo, apresentou a estrutura diamétrica em forma de exponencial negativa, isso também foi observado quando as diferentes categorias de uso foram analisadas. Tal comportamento indica estabilidade na recomposição florestal (Figura 1). A maioria das espécies classificadas como MS e MP não atingem diâmetros elevados (Parrotta et al., 1995), concentrando-se nas classes de menor diâmetro, 


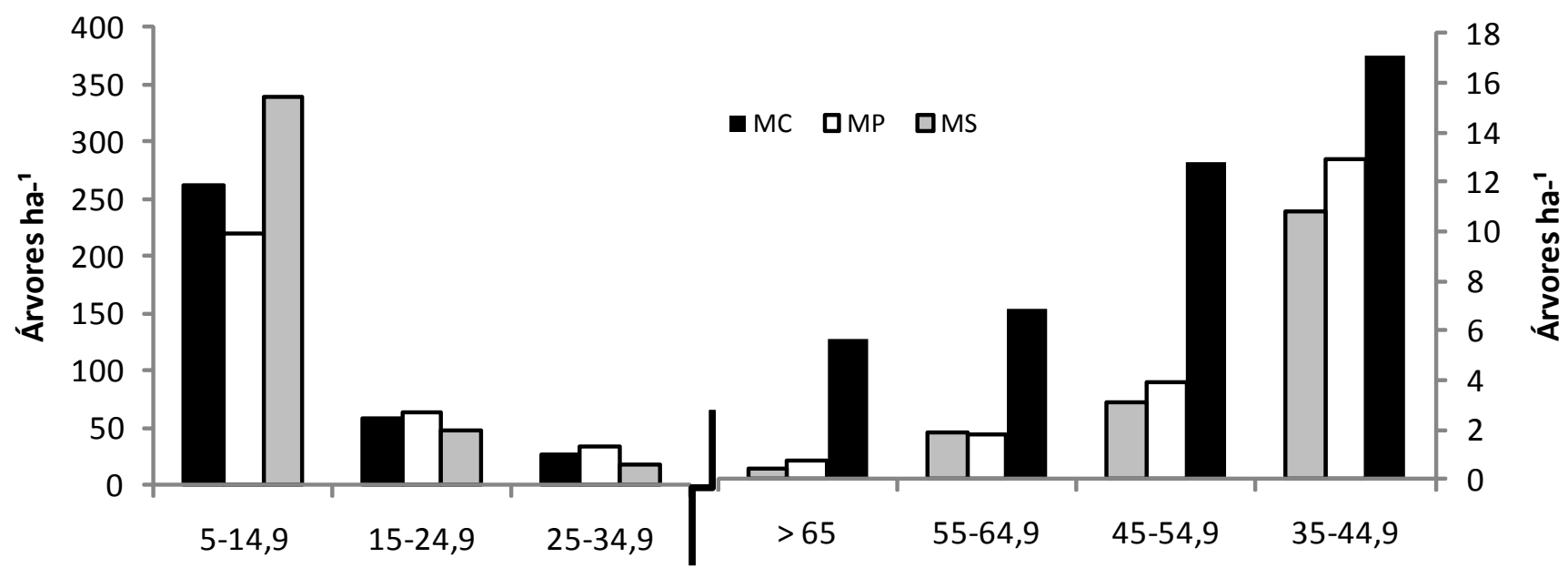

Classes de DAP (cm)

Figura 1. Distribuição dos indivíduos por classes de DAP e classificados como: espécies com valor comercial (MC); espécies potenciais (MP); e espécies sem valor comercial (MS), detectadas na Floresta Nacional do Tapajós, Km 67.

restringindo sua exploração, principalmente por conhecimento incipiente dessas espécies, o que vem impossibilitando os aspectos legais da sua exploração e, por outro lado, da falta de tecnologia industrial para o processamento de suas madeiras.

\section{Volume}

Aos 28 anos após a exploração, a área apresentou um volume de madeira de $255,6 \mathrm{~m}^{3} \mathrm{ha}^{-1}$, considerando árvores com $\mathrm{DAP} \geq 20 \mathrm{~cm}$, sendo $53 \%$ na classe $\mathrm{MC}$, $30 \%$ em MP e $17 \%$ em MS (Tabela 2). Esse volume foi superior ao encontrado na mesma área antes da exploração (1975), que foi de aproximadamente 190 $\mathrm{m}^{3} \mathrm{ha}^{-1}$. Em área não explorada inventariada em 2009 e vizinha da área deste estudo, o volume encontrado foi de $210 \mathrm{~m}^{3} \mathrm{ha}^{-1}$. Em outra área (Km 114) também na Flona do Tapajós, distante $50 \mathrm{~km}$ da área do presente estudo, foi registrado um volume de $285 \mathrm{~m}^{3} \mathrm{ha}^{-1}$, antes da exploração florestal.

As espécies que apresentaram maior volumetria na categoria MC foram, em ordem decrescente: Carapa guianensis, Tachigali chrysophylla, Couratari stellata e Jacaranda copaia, que juntas representaram $32 \%$ do volume nessa categoria. As espécies com maior volumetria na categoria MP foram, em ordem decrescente: Protium altsonii, Rinorea guianensis, Pouteria macrophylla e Cecropia sciadophylla, que juntas representaram $40,3 \%$ do volume nessa categoria. As espécies com maior volumetria classificadas como MS foram, em ordem decrescente: Bixa arborea, Sloanea spp. (duas espécies), Guatteria poeppigiana,
Neea ovalifolia e Neea sp., que juntas representaram $70,4 \%$ do volume nessa categoria, observando-se que B. arborea contribuiu com $51 \%$ desse volume.

Das espécies madeireiras registradas na área, somente 47 apresentaram o diâmetro mínimo de corte (DAP $\geq$ $50 \mathrm{~cm}$ ), que juntas, somaram quase um terço do volume total dos indivíduos amostrados na área $\left(80,6 \mathrm{~m}^{3} \mathrm{ha}^{-1}\right)$, mas considerando a retirada das espécies proibidas para exploração (Bertholletia excelsa e Hevea brasiliensis), o volume potencial a ser explorado seria de $75,5 \mathrm{~m}^{3} \mathrm{ha}^{-1}$ (Tabela 2). Vale salientar que não foram considerados os critérios da legislação que regulamenta o PMFS (Plano de Manejo Florestal Sustentável), no que diz respeito à seleção de espécies para exploração (árvores raras, matrizes e $10 \%$ de remanescentes), ainda deve-se ressaltar que desse volume potencial não foi considerada a qualidade de fuste e árvores danificadas naturalmente, o que vem a reduzir o volume potencial para colheita.

Comparando o volume para o corte -MC (DAP $\geq 50$ $\mathrm{cm})$ registrado em 1981 com o volume incrementado até 2007, obteve-se um aumento $137,4 \%$, incremento de $43,7 \mathrm{~m}^{3}$ ha $^{1}$ (Tabela 2). O maior incremento volumétrico foi observado nas espécies sem valor comercial (MS), com $361 \%\left(11,2 \mathrm{~m}^{3}\right.$ ha $\left.{ }^{1}\right)$. Supõe-se que com a abertura do dossel florestal pela exploração, as MS foram favorecidas pela maior entrada de luz, diminuição da competição por nutrientes e rápida colonização das clareiras de algumas dessas espécies. Por outro lado, as espécies MP com incremento de 49,1\% $\left(4,7 \mathrm{~m}^{3} \mathrm{ha}^{1}\right)$ sugerem que esse grupo de espécies ocupa a posição intermediária 
do estrato vertical da floresta e que sofreram o maior impacto florestal e/ou mesmo são espécies de ciclos de vida mais curto, sugerindo um maior dinamismo de entradas e saídas de indivíduos dessa categoria, espécies que alcançam também pequenos diâmetros (DAP $<50$ $\mathrm{cm}$, Tabela 2).

O IPA em volume da categoria MC foi de $2,19 \mathrm{~m}^{3} \mathrm{ha}^{-1}$ ano $^{-1}$, contudo, o incremento periódico anual (IPA) das árvores com DAP $\geq 50 \mathrm{~cm}$ acumulam $82 \%$ do total $(1,8$ $\mathrm{m}^{3} \mathrm{ha}^{-1}$ ano $^{-1}$ ), identificando que a grande dinâmica da biomassa florestal concentra-se nas classes de árvores com grandes diâmetros.

O Monitoramento contínuo do crescimento detectou que as árvores com maiores diâmetros têm apresentado maior incremento diamétrico, de modo que a classe com DAP $<25 \mathrm{~cm}$ apresentou as menores taxas $(0,23$ $\mathrm{cm} / \mathrm{ano}$ ), enquanto a comunidade toda revelou um crescimento de $0,25 \mathrm{~cm}^{2} \mathrm{ano}^{-1}$ (Tabela 2).

Analisando o incremento em volume das espécies exploradas em 1979, as com maior incremento foram: C. guianensis $\left(0,30 \mathrm{~m}^{3} \mathrm{ha}^{-1} \mathrm{ano}^{-1}\right)$ e $V$. michelii $(0,13$ $\mathrm{m}^{3} \mathrm{ha}^{-1}$ ano $^{-1}$ ) (Figura 2). Apesar de C. guianensis ter diminuído sua densidade em 26 anos de avaliação, pode se considerar uma espécie dominante na comunidade e que foi favorecida pela exploração.

A exploração madeireira realizada sem critérios ecológicos na escolha das espécies para o corte poderá ser um risco para a biodiversidade existente. O comportamento das espécies remanescentes após a colheita florestal é diferente se comparada à floresta primária, pois muda toda a estrutura vertical da floresta, o que vem a favorecer certos grupos de espécies remanescentes e prejudicar o crescimento e estabelecimento de outras, o que pode exigir longos períodos de dinâmicas sucessionais para algumas espécies se restabelecerem na área. Fato esse constatado na dominância de certas espécies nesse novo estrato florestal e que não foram dominantes antes da exploração, a exemplificar, B. arborea, espécies do gêneros Cecropia, Protium e Inga.

Um novo ciclo de corte deveria prever o manejo diferenciado por espécie, considerando a abundância e dominância da espécie na área, de modo a balancear o estoque remanescente nas características ecológicas e sucessionais das espécies. Braz (2010) sugere um único ciclo de corte com taxas de corte diferenciadas por agrupamento de espécies em conformidade com o incremento das mesmas. O planejamento tem que levar em consideração a capacidade de recomposição, indicada pelo incremento individual das espécies e a análise da sua distribuição diamétrica. Outros critérios ecológicos também devem ser observados, como: o planejamento de diferentes indivíduos a serem preservados para uma mesma espécie em função dos diferentes graus de raridade apresentados pela espécie nas diferentes comunidades (Alves \& Miranda, 2008) e a análise do diâmetro mínimo de reprodução de espécies madeireiras (Fonseca et al., 2008).

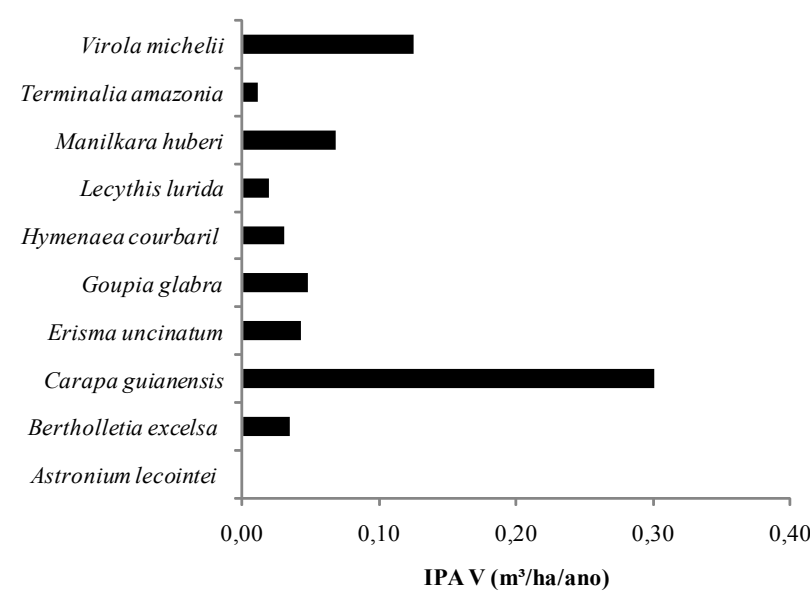

Figura 2. Incremento Periódico Anual em volume (IPAv) de 10 espécies exploradas na Floresta Nacional do Tapajós, considerando 26 anos (1981-2007).

A distribuição diamétrica do volume foi crescente nas espécies MC, decrescente nas MP e descontínua nas MS (Figura 3). A categoria MC apresentou o volume concentrado (59,3\%) nas classes superiores (DAP $\geq 50$ $\mathrm{cm})$, se diferenciando da categoria MP que apresentou concentrado $(81,6 \%)$ nas classes inferiores (DAP $<50$ $\mathrm{cm})$. Identificando novamente que um dos requisitos determinantes por ter valor comercial reconhecido é limitado pelo diâmetro máximo atingido, observando que praticamente a maioria das espécies classificadas como MP são espécies que biologicamente apresentam limites diamétricos inferiores aos estabelecidos pela indústria madeireira e/ou legislação ambiental.

As espécies MS, com distribuição volumétrica levemente decrescente (DAP $<50 \mathrm{~cm}=66,9 \%$ ), basicamente justificada pela contribuição de Bixa arborea, espécie dominante pós a exploração florestal e que apresenta indivíduos com grandes diâmetros.

Embora ocorra um rápido decréscimo do volume entre as classes $60 \leq \mathrm{DAP}<69,9$, isso indica que o estoque explorado no período de 28 anos não foi 
recuperado nessa classe diamétrica. Obviamente, a maior intensidade exploratória ocorreu nesta classe de diâmetro e da mesma forma, biologicamente, esse é o limite diamétrico de muitas espécies. $\mathrm{O}$ destaque na classe DAP $>70 \mathrm{~cm}$, certamente, se trata do estoque remanescente das espécies que não foram exploradas e/ou apresentaram qualidade de fuste desclassificadas à exploração. Tudo isso vem realçar que o estoque da biomassa é rapidamente recuperado, embora qualitativamente esse estoque seja composto por indivíduos de menores diâmetros e da mesma forma de diferentes espécies comparado ao estoque original, antes da exploração.

Tabela 2. Comparação do volume $\left(\mathrm{m}^{3} \mathrm{ha}^{-1}\right)$ e o IPA (Incremento Periódico Anual) considerando o intervalo de 1981-2007, nas categorias MC, MP e MS, na Floresta Nacional do Tapajós, Km-67.

\begin{tabular}{|c|c|c|c|c|}
\hline \multicolumn{5}{|c|}{ Classificação $^{* 1}$} \\
\hline & MC & MP & MS & \\
\hline 1981 & & $\left(\mathrm{~m}^{3} \mathrm{ha}^{-1}\right)$ & & Total \\
\hline $\mathrm{DAP}<50 \mathrm{~cm}$ & 44,66 & 43,57 & 15,48 & 103,71 \\
\hline $\mathrm{DAP} \geq 50 \mathrm{~cm}$ & 34,19 & 9,53 & 3,10 & 46,82 \\
\hline Total & 78,84 & 53,11 & 18,58 & 150,53 \\
\hline 2007 & & $\left(\mathrm{~m}^{3} \mathrm{ha}^{-1}\right)$ & & \\
\hline $\mathrm{DAP}<50 \mathrm{~cm}$ & 54,76 & 62,87 & 28,87 & 146,49 \\
\hline $\mathrm{DAP} \geq 50 \mathrm{~cm}$ & 80,59 & 14,21 & 14,29 & 109,09 \\
\hline Total & 135,34 & 77,08 & 43,16 & 255,58 \\
\hline Diferença & & $81-2007\left(\mathrm{~m}^{3} \mathrm{~h}\right.$ & & \\
\hline $\mathrm{DAP}<50 \mathrm{~cm}$ & 10,10 & 19,30 & 13,38 & 42,78 \\
\hline $\mathrm{DAP} \geq 50 \mathrm{~cm}$ & 46,40 & 4,68 & 11,20 & 62,28 \\
\hline Total & 56,50 & 23,98 & 24,58 & 105,05 \\
\hline IPA V & & $\left(\mathrm{m}^{3} \mathrm{ha}^{-1} \mathrm{ano}^{-1}\right)$ & & \\
\hline $\mathrm{DAP}<50 \mathrm{~cm}$ & 0,39 & 0,75 & 0,52 & 1,66 \\
\hline $\mathrm{DAP} \geq 50 \mathrm{~cm}$ & 1,80 & 0,18 & 0,43 & 2,41 \\
\hline Total & 2,19 & 0,93 & 0,95 & 4,07 \\
\hline IPA D & & $\left(\mathrm{cm} \mathrm{ano}^{-1}\right)$ & & $\mathrm{n}$ \\
\hline $5-24,9$ & $0,27(973)$ & $0,23(1.555)$ & $0,19(961)$ & $0,23(3.489)$ \\
\hline $25-44,9$ & 0,55 (219) & $0,24(172)$ & $0,49(42)$ & $0,41(433)$ \\
\hline $45-64,9$ & $0,45(45)$ & $0,32(16)$ & $0,49(4)$ & $0,43(65)$ \\
\hline $65-84,9$ & $0,63(10)$ & $0,43(2)$ & $0,12(1)$ & $0,56(13)$ \\
\hline $85-104,9$ & $0,53(2)$ & - & $0,57(2)$ & $0,57(4)$ \\
\hline$\geq 105$ & $0,71(1)$ & - & - & $0,71(1)$ \\
\hline Total & $\begin{array}{c}0,33 \\
(1.250)\end{array}$ & $0,23(1.745)$ & $0,2(1.010)$ & $0,254.005$ \\
\hline
\end{tabular}

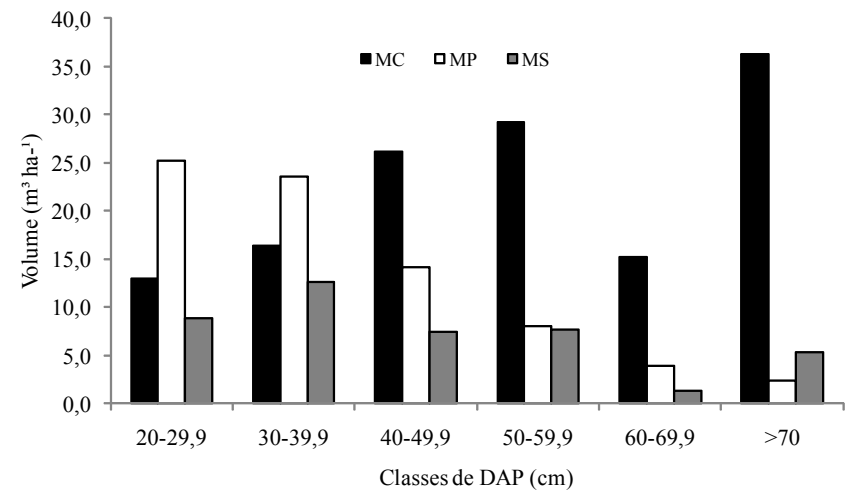

Figura 3. Distribuição do volume das espécies Madeireiras, Potenciais e Sem valor madeireiro em relação às classes diamétricas. Dados observados em área explorada na Floresta Nacional do Tapajós, Km-67, em 2007. Madeireiras (MC), Potenciais (MP) e Sem valor madeireiro (MS).

\section{Dinâmica e balanço}

$\mathrm{Na}$ comparação da recuperação das dez espécies dominantes antes da exploração (1975) com DAP $\geq 45$ cm (Figura 4A), o balanço em termos de abundância foi negativo para oito espécies e positivo somente para as espécies G. glabra e V. michelii, mas considerando o volume, V. michelii apresentou balanço positivo. Porém, usando a mesma comparação para as dez espécies dominantes, após 28 anos da exploração, com DAP $\geq 45 \mathrm{~cm}$ (Figura 4B), observou-se a mudança para um novo grupo de espécies, mantendo apenas duas espécies (C. guianensis e $V$. michelii) e, por outro lado, agora inversamente, apenas três espécies com balanço negativo em volume (C. guianensis, $C$. stellata e Perebea guianensis), embora C. stellata ainda tenha apresentado saldo positivo para abundância. Ressalta-se que das dez espécies dominantes para a classe DAP $\geq 45 \mathrm{~cm}$, apenas duas espécies (C. guianensis e $V$. michelii) se mantiveram dominantes após 28 anos da exploração. As espécies $C$. guianensis, E. uncinatum, $M$. huberi e $B$. excelsa apresentaram um leve déficit na densidade, mas no volume, com exceção de $C$. guianensis, o déficit foi superior a $50 \%$. A exploração não favoreceu as espécies A. lecointei, L. lurida, H. courbaril, e T. amazonia que continuam após 28 anos com déficit tanto em densidade $(>60 \%)$ como em volume ( $>80 \%)$ (Figura $4 \mathrm{~A})$. Da mesma maneira, no grupo das dez espécies dominantes antes da exploração, todas foram classificadas como MC; do contrário, das dez espécies dominantes após 28 anos da exploração, apenas três espécies foram classificadas como MC. 
A

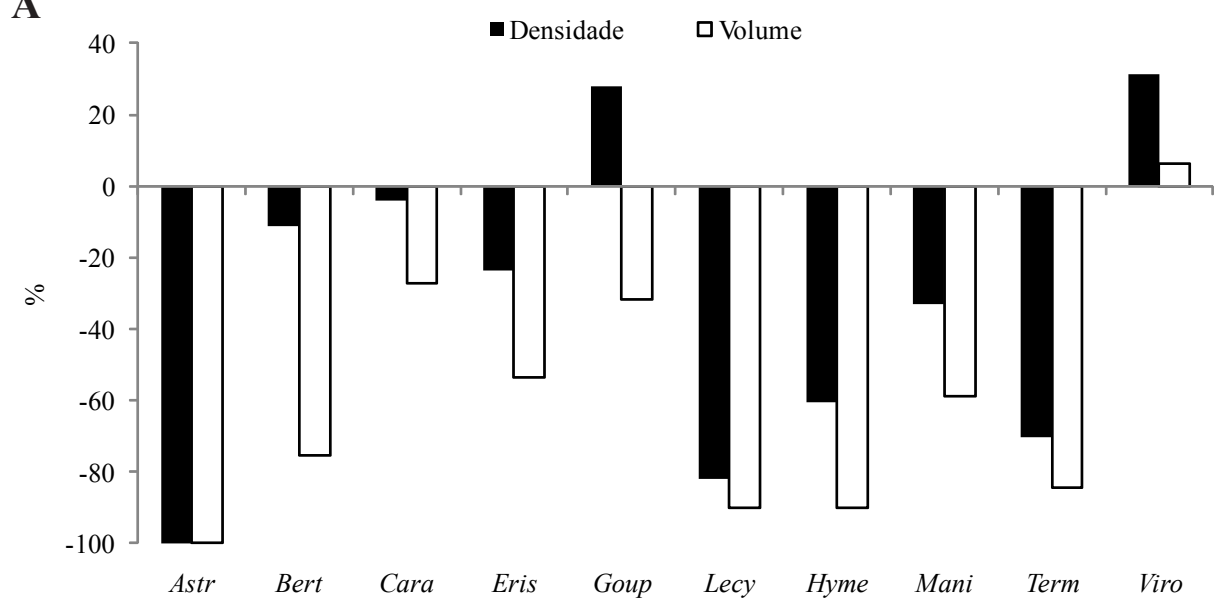

B

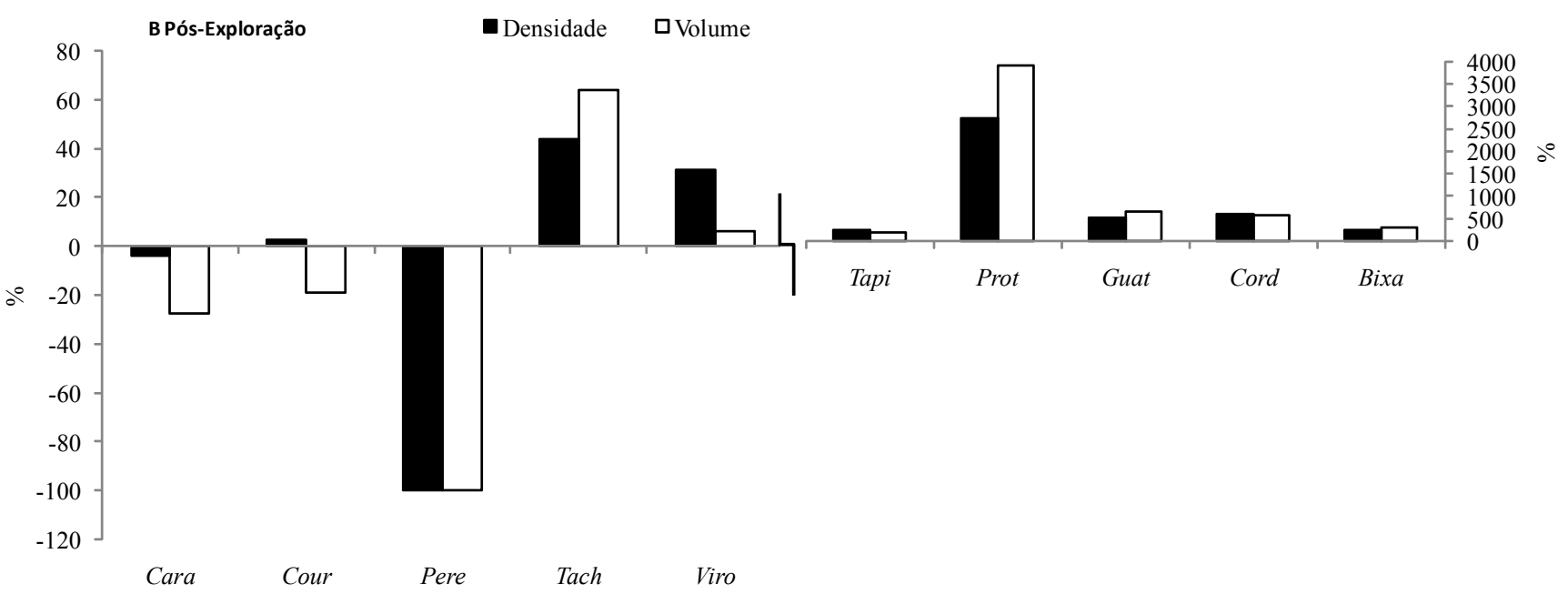

Figura 4. Comparação do volume das dez espécies com maior abundância com DAP $\geq 45 \mathrm{~cm}$, em porcentagem, o balanço da biomassa volumétrica observada antes da colheita (1975) e após a colheita florestal (2007); (A) antes da colheita (1975) ; (B) após a colheita florestal (2007). Astr: Astronium lecointei, Bert: Bertholletia excelsa, Cara: Carapa guianensis, Eris: Erisma uncinatum, Goup: Goupia glabra, Lecy: Lecythis lurida, Hyme: Hymenaea courbaril, Mani: Manilkara huberi, Term: Terminalia amazonia, Viro: Virola michelii, Cour: Couratari stellata, Pere: Perebea guianensis, Tach: Tachigali chrysophylla, Tapi: Tapirira guianensis, Prot: Protium altsonii, Guat: Guatteria poeppigiana, Cord: Cordia bicolor e Bixa: Bixa arborea.

Supõe-se que as espécies que obtiveram saldo positivo na recuperação do estoque de árvores DAP $\geq 45 \mathrm{~cm}$ foram favorecidas pelo estoque das árvores remanescentes abaixo do diâmetro de corte, que por sua vez apresentaram características ecológicas favoráveis ao ambiente com maior radiação solar gerada pela exploração. Já para a maioria das espécies da classe MC, o saldo após 28 anos da exploração é negativo para essas. Estima-se um período praticamente centenário para sua completa reposição. Tal suposição encontra-se em conformidade as várias simulações que particularizaram os estudos, como variáveis de demografia e dados genéticos populacionais de algumas espécies florestais, as quais indicaram a necessidade de ciclos de corte superiores a 60 anos (Sist et al., 2003; Schulze et al., 2005; Gardingen et al., 2006). Portanto, deve-se realçar que a colheita da madeira na área estudada foi de alta intensidade $\left(72,5 \mathrm{~m}^{3} \mathrm{ha}^{-1}\right)$, praticamente três vezes o volume legalmente permitido de ser explorado, sugerindo a necessidade de monitoramento de áreas manejadas com a intensidade de colheita atualmente vigentes. 
Da mesma forma, se comparada a recuperação das dez espécies dominantes antes e após a exploração, foram consideradas as mesmas espécies no intervalo diamétrico inferior a $45 \mathrm{~cm}$, para assim comparar o estado da recuperação desse mesmo grupo de espécies (Figura 5A e 5B). Nesse grupo das dez espécies dominantes antes da exploração, somente as espécies A. lecointei e $M$. huberi apresentaram balanço negativo. Já no período de 28 anos após a exploração nesse grupo, unicamente fica em destaque $P$. guianensis, a qual recuperou o estoque observado antes da exploração. Supõe-se que a espécies $P$. guianensis, pela identificação errônea da época, é atualmente representada por um grande grupo de espécies vulgarmente conhecidas por muiratingas (espécies de vários gêneros da família Moraceae). Ainda é importante observar, além da mudança do grupo de espécies dominantes antes e após a exploração, o aumento explosivo em densidade e volume de $B$. arborea e P. altsonii. Independente desse desequilíbrio, tem-se positivamente que o estoque remanescente das espécies com DAP $\geq 45 \mathrm{~cm}$ é superior ao do observado antes da exploração.
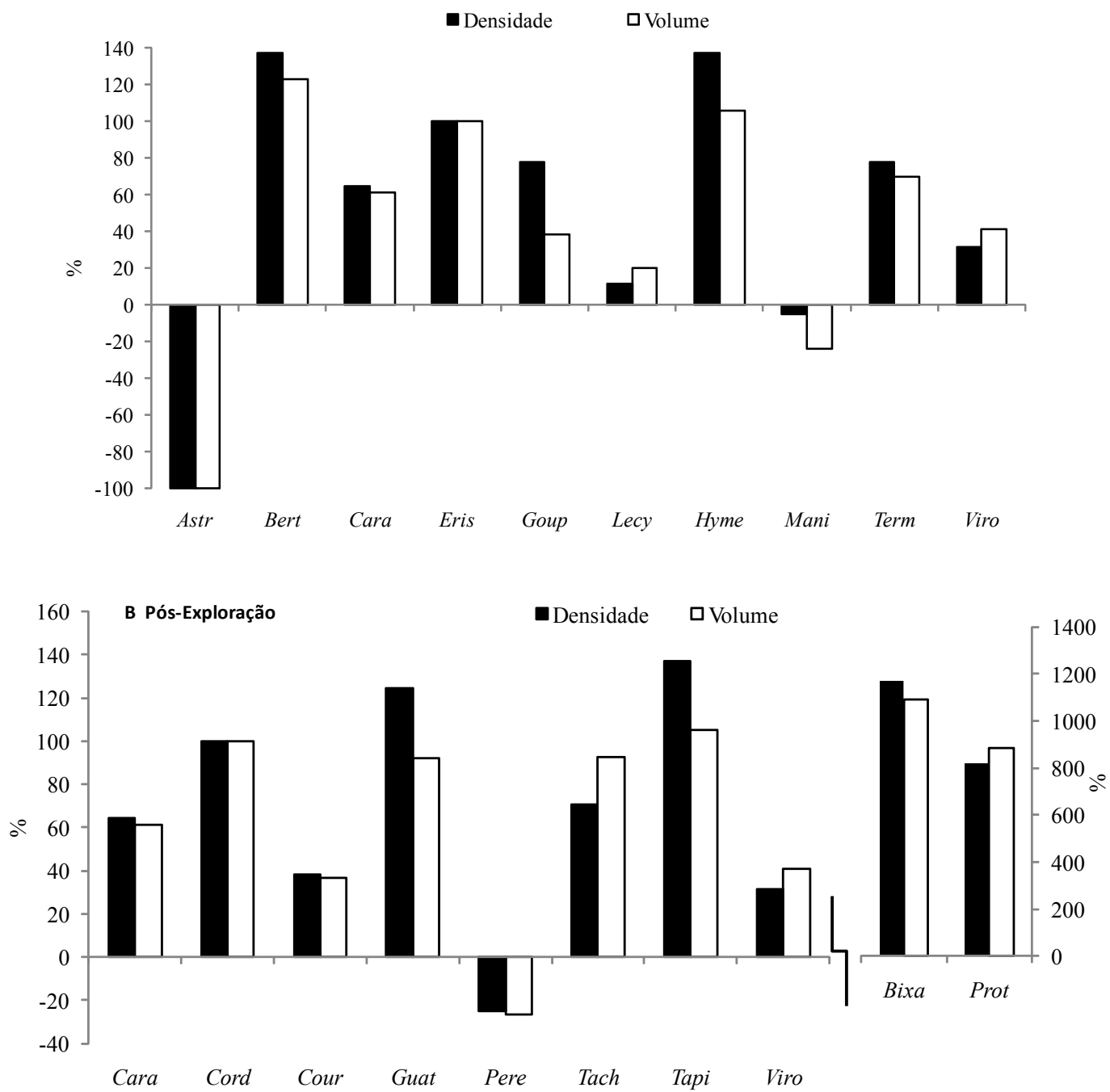

Figura 5. Comparação do volume das dez espécies com maior abundância com $30 \mathrm{~cm} \leq \mathrm{DAP}<45 \mathrm{~cm}$, em porcentagem, o balanço da biomassa volumétrica observada antes da colheita (1975) e após a colheita florestal (2007); (A) antes da colheita (1975); (B) após a colheita florestal (2007). Astr: Astronium lecointei, Bert: Bertholletia excelsa, Cara: Carapa guianensis, Eris: Erisma uncinatum, Goup: Goupia glabra, Lecy: Lecythis lurida, Hyme: Hymenaea courbaril, Mani: Manilkara huberi, Term: Terminalia amazonia, Viro: Virola michelii, Cour: Couratari stellata, Pere: Perebea guianensis, Tach: Tachigali chrysophylla, Tapi: Tapirira guianensis, Prot: Protium altsonii, Guat: Guatteria poeppigiana, Cord: Cordia bicolor e Bixa: Bixa arborea. 
Nota-se a mudança no cenário das composições das espécies para a futura colheita, evidenciando fortemente a mudança do grupo de espécies dominantes (Figura 4 e 5). Por outro lado, também se destaca um pequeno grupo de espécies que nitidamente encontraram condições ambientais favoráveis após a exploração, o que as levaram a superar o estoque apresentado antes da exploração. Entre estas, destacam-se: P. altsonii, $B$. arborea, C. bicolor, G. poeppigiana, T. guianensis, $T$. chrysophylla e $V$. michelii. Praticamente todas essas espécies não apresentam valor comercial, principalmente na região de abrangência do presente estudo, mostrando a necessidade de estudos tecnológicos para uso dessa imensa biomassa florestal, que é praticamente o estoque da futura colheita florestal, seja ela do primeiro ciclo de corte. Isto está em conformidade aos resultados deste estudo, em que se identificou uma das primeiras experiências de exploração florestal monitorada em longo prazo, em período de 28 anos na Amazônia legal, em uma exploração florestal pesada, sem considerar o volume explorado por espécie, representando um volume total explorado superior a duas vezes ao que é admissível atualmente pela legislação florestal.

\section{Conclusão}

A área apresentou 85 espécies atualmente comercializadas, além de 75 espécies (MP) não comercializadas, mas com características que podem propiciar a sua exploração, sendo indicadas para análises tecnológicas.

O ciclo de corte de 30 a 35 anos é viável unicamente se for planejado praticamente com novas espécies, que não foram exploradas na primeira colheita florestal. Contudo, nesse estudo, realça-se fortemente que a colheita foi muito pesada, o que contribuiu para a não recuperação do volume das espécies exploradas na primeira colheita, o que diminui a capacidade do incremento por ter deteriorado a estrutura remanescente. Estima-se um volume de $75,5 \mathrm{~m}^{3} \mathrm{ha}^{-1}$ de madeiras comerciais aptas para o planejamento da colheita, indicando a possibilidade de um novo ciclo de corte, embora tais espécies continuem com balanço negativo se comparado ao estoque original (antes da primeira colheita). Isso realça que a estrutura florestal foi completamente alterada em relação à original, mesmo com a recuperação da biomassa. A qualidade da floresta em termos de madeira de valor comercial é muito menor, sugerindo avanços tecnológicos para o uso e processamento dessa nova diversidade de recursos florestais.

As espécies exploradas há 28 anos apresentaram balanço negativo, mas as espécies, principalmente as pioneiras e não exploradas, beneficiaram-se pela exploração e obtiveram um balanço positivo tanto em volume como em densidade.

As espécies nas classes diamétricas exploradas não recuperaram o estoque original. Porém, a recuperação do futuro estoque destas espécies (DAP $\geq 50 \mathrm{~cm}$ ) está garantido e é inclusive superior ao observado antes da exploração.

As espécies responderam diferentemente à exploração florestal, indicando que cada espécie tem o seu comportamento e tempo de regeneração.

Sugere-se o planejamento da exploração por espécie, ou grupos de espécies com mesmo incremento em conformidade com o que a floresta pode incrementar, a distribuição diamétrica e espacial remanescente. Tais procedimentos podem favorecer a recuperação equilibrada entre as espécies, promovendo uma maior produtividade florestal e sustentabilidade.

\section{Agradecimentos}

Os autores agradecem ao $\mathrm{CNPq}$, pelo apoio financeiro (Projeto Universal/CNPq - N 477289/2007-0) e Projeto Floresta em Pé- CFBRA e a bolsa de iniciação científica cedida aos autores; à Embrapa Amazônia Oriental, pelo apoio institucional, e à dedicação e apoio nas atividades de campo do Sr. Nilson de Souza Carvalho, Raimundo Nonato Feitosa (in memorian), Valdemir Rodrigues de Lira e Lúcio Reginaldo Seixas.

\section{Referências}

ALDER, D.; SILVA, J.N.M. Sustentabilidade da produção volumétrica: Um estudo de caso na Floresta Nacional do Tapajós com o auxílio do modelo de crescimento Cafogrom. In: SILVA, J.N.M; SILVA, S.M.A. da; YARED, J.A.G. A silvicultura na Amazônia Oriental: contribuições do projeto Embrapa/DFID. Belém: Embrapa Amazônia Oriental. p. 459. 2001.

ALVES, J.C.Z.; MIRANDA, I. S.; Análise da estrutura de comunidades arbóreas de uma floresta amazônica de Terra Firme aplicada ao manejo florestal. Acta Amazonica, vol. 38, n. 4. p. 657- 666, 2008.

BARROS, A.C.; VERÍSSIMO,A. A Expansão madeireira na Amazônia: Impactos e perspectivas para o desenvolvimento sustentável no Pará. Belém: IMAZON, 2002. 180 p. 
BRAZ, E.M. Subsídios para o planejamento do manejo de florestas tropicais da Amazônia. Santa Maria: UFSM, 2010. p. 237. Tese de Doutorado do Programa de Pós-Graduação em Engenharia Florestal, 2010.

CARVALHO, J.O.P. de. Inventário diagnóstico da regeneração natural da vegetação em área da Floresta Nacional do Tapajós. Belém: Embrapa Amazônia Oriental, 1980. p. 23.(EmbrapaCPATU. Boletim de pesquisa, 2).

COSTA FILHO, P.P.; COSTA, H.B.; AGUIAR, O.R. de; Exploração mecanizada da floresta tropical, úmida sem babaçu. Belém: Embrapa Amazônia Oriental, 1980. p. 29.(Embrapa-CPATU. Circular técnico 9).

COSTA, D.H.M.; FERREIRA, C.A.P.; SILVA, J.N.M.; LOPES, J. do C.A.; CARVALHO, J.O.P. de. Potencial madeireiro de florestais densas no município de Moju, estado do Pará. Belém: Embrapa Amazônia Oriental, 1998. p. 33. (Embrapa-CPATU. Documentos, 121).

DUBOIS, J. Preliminary Forest management guidelines for the National Forest of the Tapajós. Belém: [s.n], 1976. p. 42. SF./ FAO/BRA- 71-545, PRODEPEF/ Northern Region.

FONSECA, M.G.; VIDAL, E.; SANTOS, F.A.M. Efeito da exploração madeireira sobre o número de indivíduos férteis de três espécies arbóreas comerciais na Amazônia oriental, Acta Amazonica, v. 38, n.4. p. 681 - 686, 2008.

FRANCEZ, L.M. de B.; CARVALHO, J.O.P. de; JARDIM, F.C. da S. Mudanças ocorridas na composição florística em decorrência da exploração florestal em uma área de floresta de Terra firme na região de Paragominas, PA. Acta Amazonica,v. 37, n.2, p. 219 228, 2007.

GARDINGEN, P. R. van; VALLE, D.; THOMPSON, I. Evaluation of yield regulation options for primary forest in Tapajós National Forest, Brazil. Forest Ecology and Management, v. 231, p. 184-195, 2006.

IDEFLOR - Instituto de Desenvolvimento Florestal do Estado do Pará. Plano Anual de Outorga Florestal 2009. Belém: IDEFLOR, 2008. 68 p.

LOPES, J. do C.A.; CARVALHO, J.O.P. de; SILVA, J.N.M.; COUTINHO, S.C. Composição florística de uma floresta secundária três anos após o corte raso da floresta primária. Belém: Embrapa Amazônia Oriental, 1989. p. 25.(EmbrapaCPATU. Boletim de Pesquisa, 100).

LOPES, W.P.; SILVA, A.F.; SOUZA, A.L.; MEIRA NETO, J.A.A. Estrutura fitossociológica de um trecho de vegetação arbórea no Parque Estadual do Rio Doce - Minas Gerais, Brasil. Acta bot. bras. v.16, n. 4, p. 443-456, 2002.

OLIVEIRA, L.C.; COUTO, H.T.Z do.; SILVA, J.N.M.; CARVALHLO, J.O.P. de. Efeito da exploração de madeira e tratamentos silviculturais na composição florística e diversidade de espécies em uma área de 136 ha na Floresta Nacional doTapajós, Belterra, Pará. Scientia Forestalis. v.69, p.62-76, 2005.

PARROTTA, J. A.; FRANCIS, J. K.; ALMEIDA, R. R. de. Trees of the Tapajós: a photographic field guide. Rio Piedras: USDA, Forest Service, International Institute of Tropical Forestry, 1995. 370 p. (USDA. For. Serv. Gen. Tech. Rep. IITF-1).
RUSCHEL, A.R. Dinâmica da composição florística e do crescimento de uma floresta explorada há 18 anos na Flona Tapajós. Belém: Embrapa Amazônia Oriental, 2008.p. 58. (Série documentos, 341).

RUSCHEL, A.R.; GUERRA, M.P.; MOERSCHBACHER, B.M.; NODARI, R.O. Valuation and characterization of timber species in remnants of the Alto Uruguay River ecosystem, southern Brazil. Forest Ecology and Management. v.217, p.103-116, 2005.

RUSCHEL, A.R.; NODARI, E.S.; GUERRA, M.P.; NODARI. R.O. Evolução do uso e valorização das espécies madeiráveis da floresta estacional decidual do Alto-Uruguai-SC. Ciência Florestal, v. 13, p. 153-166, 2003.

SABOGAL, C.; LENTINI, M.; POKORNY, B.; SILVA, J.M.N; ZWEEDE, J.; VERÍSSIMO, A.; BOSCOLO, M. Manejo empresarial na Amazônia brasileira. Belém: CIFOR, p 174, 2006.

SANDEL, M.P; CARVALHO, J.O.P de. Composição florística e estrutura de uma área de cinco hectares de mata alta sem babaçu na Floresta Nacional do Tapajós. Belém: Embrapa Amazônia Oriental, 2000. 19 p.(Embrapa Amazônia Oriental. Documentos, 63).

SCHULZE, M.; VIDAL, E.; GROGAN, J.; ZWEEDE, J.; ZARIN, D. As melhores práticas e normas de manejo atuais não sustentarão a produção de madeira nas florestas da Amazônia. Ciência Hoje, v. 214, p. 66-69, 2005.

SFB - Serviço Florestal Brasileiro. Plano Anual de Outorga Florestal 2010. Brasília: SFB, 2009. 83 p.

SILVA, J.N.M. The behaviour of the tropical rain forest of the Brazilian Amazon after logging. 1989. 302p. Tese (Doutorado em Ciências Florestais) - University of Oxford, Oxford, 1989.

SILVA, J.N.M.; ARAÚJO, S.M.; Equação de volume para árvores de pequeno diâmetro, na Floresta Nacional do Tapajós. Boletim de Pesquisa Florestal, n.16-25. 1984.

SILVA, J.N.M.; CARVALHO, J.O.P. de; LOPES, J do. C.A. Inventário florestal de uma área experimental na Floresta Nacional do Tapajós. Boletim de Pesquisa Florestal, Colombo, $\mathrm{n}$. 10/11, p. 38-110, 1985.

SILVA, J.N.M.; CARVALHO, J.O.P. de; LOPES, J do. C.A.; CARVALHO, M.S.P. de. Equação de volume para a Floresta Nacional do Tapajós. Boletim de Pesquisa Florestal, n.8-9, p.5063, 1984.

SIST, P., FERREIRA, F.N. Sustainability of reducedimpact logging in the eastern Amazon. Forest Ecology and Management. 243, p.199-209. 2007.

SIST, P.; SHEIL D.; KARTAWINATA K.; PRIYADI, H. Reduced impact logging in Indonesian Borneo: some results confirming the need for new silvicultural prescriptions. Forest Ecology and Management, v. 179, p.415-427, 2003.

SOUZA, D.R.; SOUZA, A.L.; SILVA, M.L.; RODRIGUES, F.L.; Ciclo de corte econômico ótimo em floresta ombrófila densa de terra firme sob manejo florestal sustentável, Amazônia Oriental. Revista Árvore, Viçosa-MG, v.28, n.5, p.681-689, 2004.

Recebido em 15 de julho de 2010 e aprovado em 18 de novembro de 2010 
